\title{
Management of internal inflammatory root resorption with the aid of cone beam computed tomography: A case report
}

\author{
Neha Arora ${ }^{*}$, Hemanth Vagarali $^{2}$, Madhu Pujar ${ }^{3}$, Veerendra M Uppin $^{4}$, Manjula Kittur $^{5}$ \\ ${ }^{1,5}$ Post Graduate, ${ }^{2,4}$ Professor, ${ }^{3}$ Professor and HOD, Dept. of Conservative Dentistry and Endodontics, Maratha manadal Dental College, \\ Belagavi, Karnataka, India \\ *Corresponding Author: Neha Arora \\ Email: neha13nov@gmail.com
}

\begin{abstract}
Managing a case of internal root resorption is a tedious task.Mostly it is detected in anterior teeth where trauma is mainly responsible for its occurrence. It is a chronic pulpal inflammation condition where signs and symptoms are elicited in due course of time. Successful treatment can be rendered only after proper diagnosis and elimination of etiological factors. In this article a case report of internal root resorption is presented where treatment was instituted after thorough analysis of CBCT sections.
\end{abstract}

Keywords: Internal root resorption, Composite, CBCT.

\section{Introduction}

Internal root resorption is a chronic pulpal inflammation condition where loss of dentin occurs in a progressive manner from internal aspect of root canal due to odontoclastic activity. As a result pulpal space is filled with granulomatous tissue containing giant cells. ${ }^{1,2}$ Most of the times it is idiopathic. The presence of internal root resorption is usually confirmed through regular examinations of radiograph. The condition is usually asymptomatic and is detected coincidentally through routine radiographs where it is seen as round to oval radiolucent lesion of pulpal space. The outline of original root canal is not distorted and can be differentiated from external root resorption by changing radiographic angualtions. ${ }^{3}$ Sometimes pinkish spot on crown can be seen. ${ }^{4,5}$

The most common region where internal root resorption can be seen is cervical part of the root. ${ }^{4,5}$ Non surgical root canal therapy is the treatment of choice to hamper the destruction process by which blood supply to resorbing cells is severed and the destructive process is arrested. ${ }^{6}$

Various Materials for the treatment of internal root resorption include Biodentin, MTA, other bioceramic materials, thermoplasticized gutta-percha and composite resin. ${ }^{6,7}$ Management of the condition depends upon whether the resorption is perforating or non-perforating, the type of material that will be used depends on remaining dentin thickness and possible periodontal involvement. ${ }^{8,9}$

In this article a case report of internal root resorption is presented where treatment was instituted after thorough analysis of CBCT sections.

\section{Case Report}

A 42 year old male patient reported to the department of conservative dentistry and endodontics with chief complaint of discoloration in upper front tooth region since one year.

Clinical examination revealed slight discoloration of right maxillary central incisor.(Fig. 1) On pulp sensitivity testing the tooth did not respond, and also no pain on percussion and palpation was there. Intraoral periapical radiograph showed round radiolucency in coronal third of root of same tooth with an associated periapical radiolucency.(Fig. 2) A diagnosis of necrotic pulp with asymptomatic apical periodontitis was made. Patient was advised for CBCT to know the extent of lesion in three spatial levels.

Treatment plan was based on after analyzing CBCT images (Fig. 3 a, b \& c) wherein axial section revealed thinning of dentin on labial aspect at coronal third of root which was approximately $0.5 \mathrm{~mm}$. So it was decided to obturate the canal using hybrid technique.

Access opening was done under local anaesthesia. Access cavity revealed two openings one buccal and other palatal which is in confirmation with cbct images (Fig. 4)Working length determination was done using radiograph(Fig. 5) followed by cleaning and shaping of the canal with rotary protaper till F3 in conjunction with 3 percent sodium hypochlorite and 17 percent edta. Subsequently calcium hydroxide was used as intracanal medicament and waited for approximately one week.

In the next visit canal was reaccesed and $\mathrm{Ca}(\mathrm{OH})_{2}$ was removed by using diluted sodium hypochlorite copiously followed by selection of master cone(Fig. 6). AH Plus sealer was then mixed and applied into the canal apical to resorptive defect using lentulospiral and then the heat source was used to sear off GP (Fig. 7) followed by use of flowable composite i.e filtek Z350 to fill remaining part of canal. (Fig. 8).

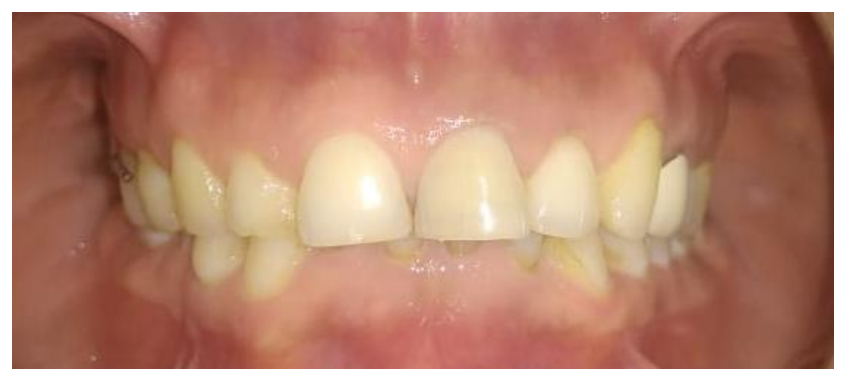

Fig. 1 
Fig. 2
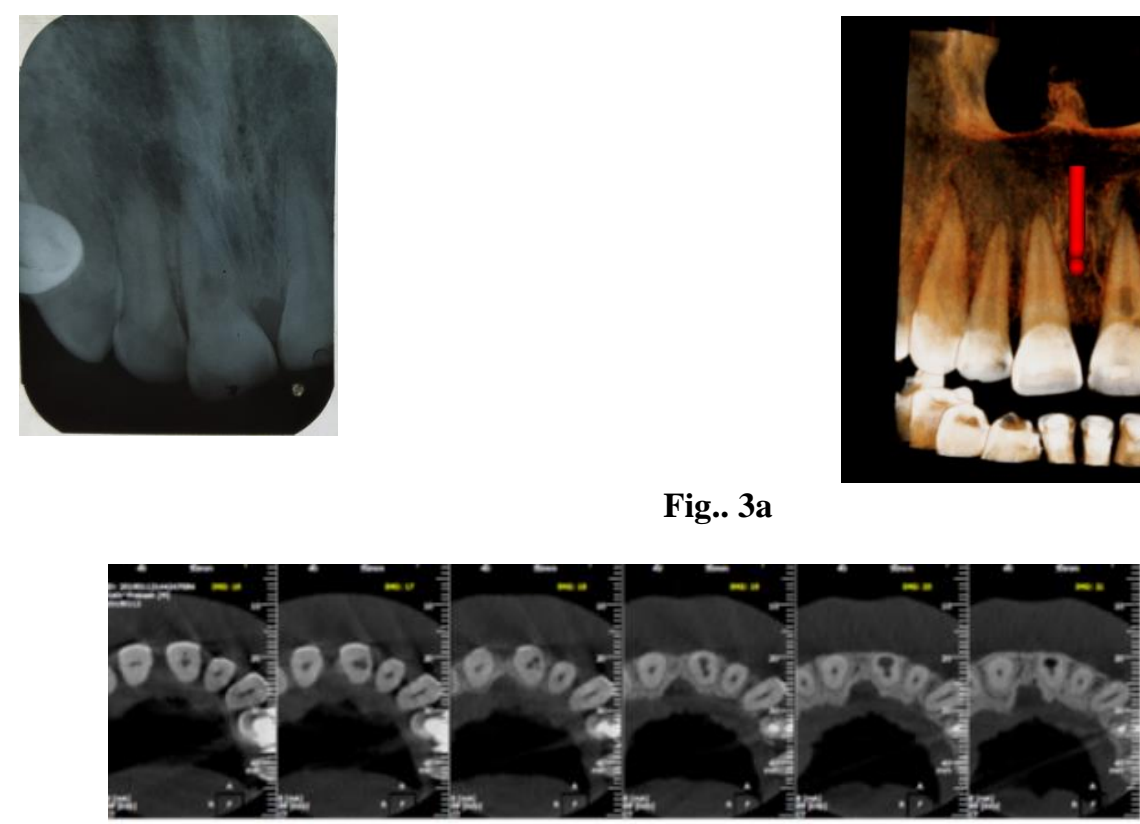

Fig. 3b
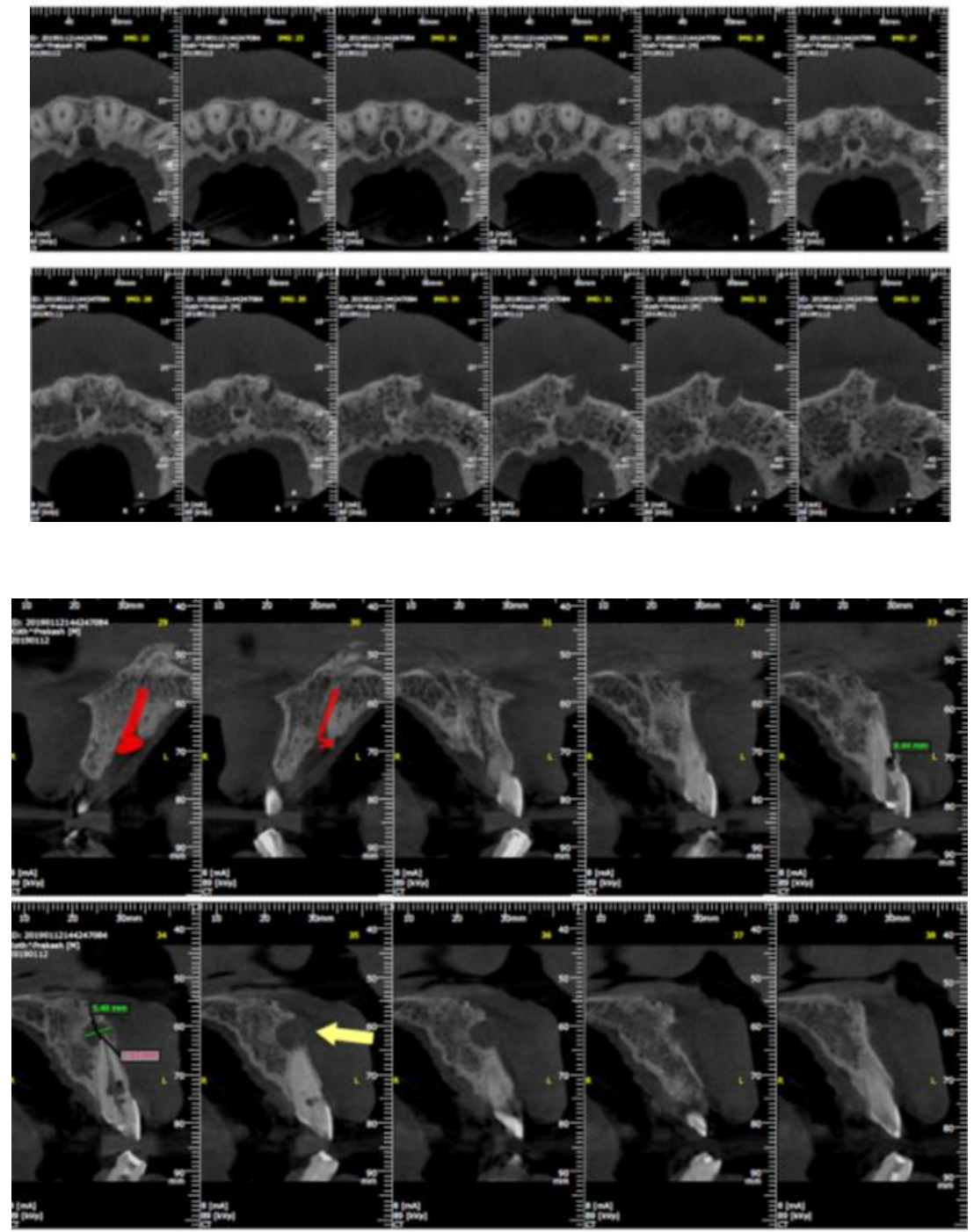

Fig. 3c 


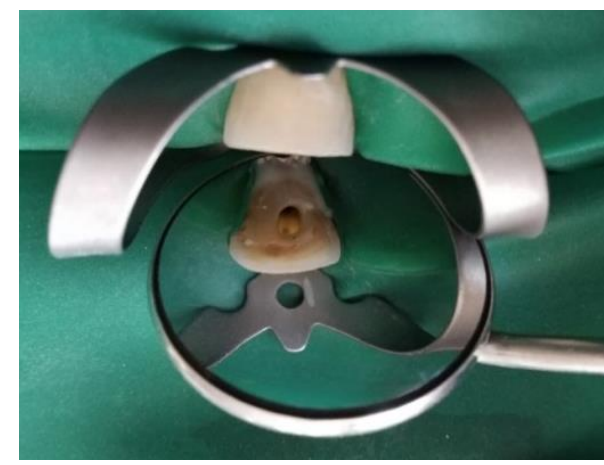

Fig. 4

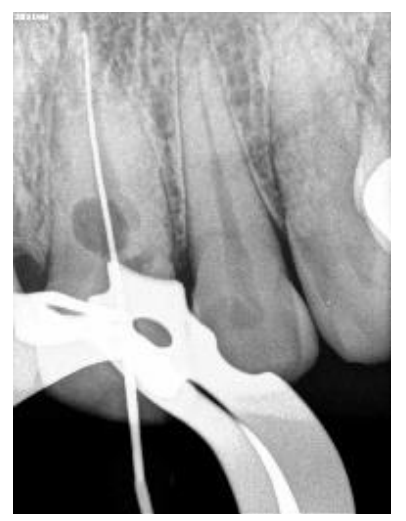

Fig. 5

Fig. 6
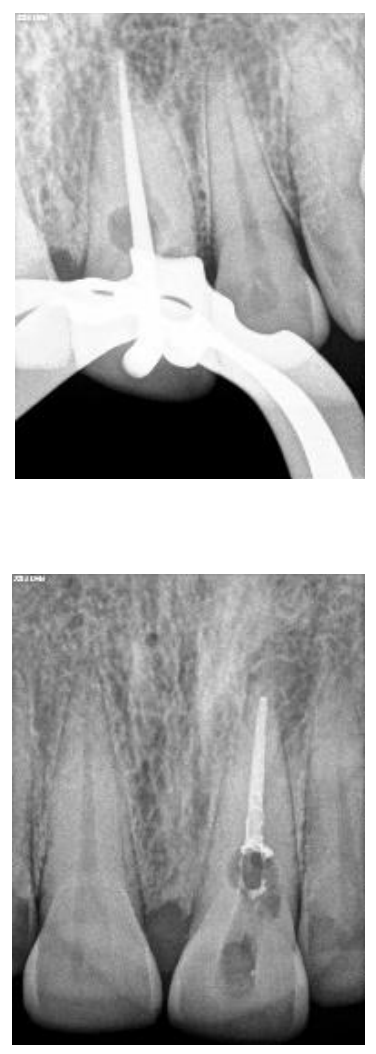

Fig. 7

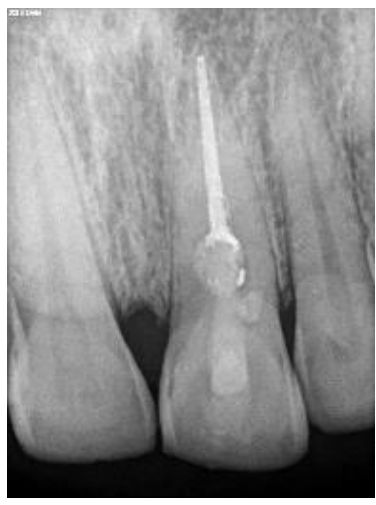

Fig. 8

\section{Discussion}

Managing a case internal root resorption is a tedious task. Early detection as well as proper differential diagnosis plays a major role in determining the successful clinical outcome. ${ }^{10-12}$

CBCT as diagnostic aid helps in accurate diagnosis and with that predictable treatment and prognosis is possible. The goal of CBCT in these type of cases is to first find the outline of the lesion, location and to see out if there is any perforation. ${ }^{13}$ In this case two openings were seen on pulpal floor one labial and one palatal. The one present labially was caused due to perforation of floor due to internal resorption.

Due to inaccessibility of resorption defects, only cleaning and shaping of the root canal space is not sufficient. Therefore, use of intracanal medicament is recommended to improve disinfection. ${ }^{1}$ Calcium hydroxide is antibacterial and effectively eradicates bacteria that remains even after chemomechanical debridement. It works with sodium hypochlorite to remove organic debris from the root canal. ${ }^{1,2}$

Obturating internal root resorption defects can be difficult. $^{14,15}$ The material that is used to seal the defect should be flowable. In this case after analyzing the CBCT sections, a treatment plan was instituted in which the canal apical to defect was obturated with GP and the remaining part of canal was reinforced with flowable composite (Filtek Z350) since the thickness of dentin on labial aspect was less than $0.5 \mathrm{~mm} .{ }^{16-18}$ Composite reinforces the remaining tooth structure. ${ }^{17}$ When root canal wall is perforated, mineral trioxide aggregate (MTA), Biodentin and other bioceramics should be used because of their excellent biocompatibility. Bioceramics are well-tolerated by periradicular tissues and has been shown to support almost complete regeneration of the periodontium. ${ }^{9}$ In addition, they also have superior sealing properties when compared with other materials. When internal resorption has rendered the tooth untreatable or unrestorable, extraction is the only treatment option.

\section{Conclusion}

Root resorption is a complex process. Internal inflammatory resorption should be controlled as soon as possible. CBCT 
aids in proper diagnosis and an appropriate treatment plan can be advocated.

\section{Source of funding}

None.

\section{Conflict of interest}

None.

\section{References}

1. Patel S, Ricucci D, Durak C, and Tay F, "Internal root resorption: a review," J Endod 2010;36(7):1107-21.

2. Haapasalo M and Endal U, "Internal inflammatory root resorption: the unknown resorption of the tooth," Endod Topics 2006;14:60-79.

3. Patel S, Pitt Ford TR. Is the resorption external or internal? Dent Update 2007;34:218-29.

4. Andreasen JO, Andreasen FM. Root resorption following traumatic dental injuries. Proc Finn Dent Soc 1992;88(1):95114

5. Patel S, Dawood A, Wilson R, Horner K, and Mannocci F, "The detection and management of root resorption lesions using intraoral radiography and cone beam computed tomography — an in vivo investigation," Int Endod J 2009;42(9):831-8.

6. Main, Mirzayan N, Shabahang S, and Torabinejad M, "Repair of root perforations using mineral trioxide aggregate: a longterm study," J Endod 2004;30(2):80-3.

7. Culbreath T. E, Davis G.M, West N.M, and Jackson A, "Treating internal resorption using a syringeable composite resin," J Am Dent Assoc 2000;131(4):493-5.

8. Heithersay GS. Management of tooth resorption. Aust Dent $J$ 2007;52:S105-21.

9. Hsien HC, Cheng YA, Lee YL, Lan WH, Lin CP. Repair of perforating internal resorption with mineral trioxide aggregate: A case report. $J$ Endod 2003;29:538-9.
10. Udagawa N, Takahashi N, Akatsu T. Origin of osteoclasts: mature monocytes and macrophages are capable of differentiating into osteoclasts under a suitable microenvironment prepared by bone marrow-derived stromal cells. Proc Natl Acad Sci U S A 1990;87:7260-4.

11. Bakland LK. Root resorption. Dent Clin North Am 1992;36:491.

12. Gulabivala K, Searson LJ. Clinical diagnosis of internal resorption: An exception to the rule. Int Endod J 1995;28:25560.

13. White SC, Pharoah MJ. The evolution and application of dental maxillofacial imaging modalities. Dent Clin North Am 2008;52(4):689-705.

14. Anantula K, Ganta AK. Evaluation and comparison of sealing ability of three different obturation techniques-Lateral condensation, Obtura II, and GuttaFlow: An in vitro study. $J$ Conserv Dent 2011;14:57-61.

15. Maxim S. Endodontic treatment of internal resorption with the aid of glass fibre reinforced root post. Endod Prac 2012;52-3.

16. Eidelman E, Rotstein I, and Gazit D, "Internal coronal resorption of a permanent molar: a conservative approach for treatment," J Clin Pediatr Dent 1997;21(4):287-90.

17. Schmoldt SJ, Kirkpatrick TC, Rutledge RE, Yaccino JM. Reinforcement of simulated immature roots restored with composite resin, mineral trioxide aggregate, guttapercha, or a fiber post after thermocycling. J Endod 2011;37:1390-3.

18. Wilkinson KL, Beeson TJ, Kirkpatrick TC. Fracture resistance of simulated immature teeth filled with resilon, gutta-percha, or composite. J Endod 2007;33:480-3.

How to cite: Arora N, Vagarali H, Pujar M, Uppin VM, Kittur M. Management of internal inflammatory root resorption with the aid of cone beam computed tomography: A case report. Indian J Conserv Endod 2020;5(1):33-6. 